\title{
Microfinance Risk Management with Work Breakdown Structure
}

\author{
Junxiang Liu \\ Asia-Australia Business College, Liaoning University, Shenyang, China \\ Email: liuxljx@hotmail.com
}

Received July $11^{\text {th }}, 2012$; revised August 24 $4^{\text {th }}, 2012$, accepted August $23^{\text {rd }}, 2012$

\begin{abstract}
Building inclusive financial system in China makes microfinance products become practical tools in solving financial difficulties of small and medium enterprises (SMEs). Discuss general management risk of microfinance under effective credit structure and then analyze the Work Breakdown Structure (WBS) in microfinance management from the perspective of project management effectiveness. Moreover, use ergonomics and probability theories to find out the effects on microfinance management through institutions with simpleness and swift. It is demonstrated that optimization of microfinance management program under inclusive financial sectors can probably be beneficial to microfinance credit risk control.
\end{abstract}

Keywords: Microfinance; Risk Management; Work Breakdown Structure

\section{Introduction}

Inclusive financial sectors, which were designed to help countries develop their own financial systems policies and strategies to achieve the Millennium Development Goals, were a concept raised by the United Nations in 2005, International Year of Microcredit. Its core content was to enable all levels of society access to a variety of financial services. Its programmatic document was Building Inclusive Financial Sectors for Development (United Nations, 2005).

At the primary stage of inclusive financial system, there is an increase tendency in the number of microfinance institutions. Moreover, these main bodies are moving in the direction towards diverse elements and multilevel structure. It has provided more opportunities to access to financial services for SMEs (Chen, 2010). There is a significant improvement in availability and proportions of banks loans for them. For instance, according to the data collected by central bank of China in 2010, $41.8 \%$ of newly loans came from SMEs loans which had occupied $30.7 \%$ of the total amount of loans.

Even though financial difficulties of SMEs, to some degree, have relieved, it is still believed that microfinance risk for SMEs is higher than that in ordinary commercial loans. In this paper, probability theory and principles of ergonomics will be used to analyze management of microfinance credit with project management methods. The paper will finally demonstrate that it is effective to reduce the risks of microfinance activities through well-designed WBS.

\section{Essential Characteristics of Project Management in Microfinance}

Inclusive financial system organically joins microfinance institutions, commercial banks and other formal financial institutions together and builds a multi-level, wide coverage and sustainable financial service system (Jiao, 2010). This makes SMEs have more opportunities to choose financial services suitable to their own specific conditions. These kinds of services include direct and indirect financing, commercial loans, small loans and so on. At present, some solutions like being listed in SME/GEM Board and using corporate bonds have settle financial difficulties of high quality SMEs, whereas more SMEs have to depend on loans from commercial banks or micro-credit funds from small-loan companies.

\section{Credit Models in Microfinance}

Commercial loans, which are in dominant position of indirect financing, mainly depend on borrowers' creditworthiness to determine whether to lend or not and the amount of loans. Not only has microfinance based on inclusive financial system characteristic of social responsibility, but it has also characteristic of commerce. In this case, the principles of commercial credit must be followed. The models of commercial loans are generally divided into joint liability loan and divided liability loan (Table 1) (Zhao, 2004; Liu \& Zhao, 2011).

Financing guarantee loan, joint guarantee loan and risk compensation fund are based on market-oriented theory of credit rationing in order to improve credit level for those whose credit rating is not high enough to access to independent responsibility loan. Its essence is to find out a second repayment sources apart from the first one, the borrower. It aims to reduce the lenders' risk. Muhammad Yunus, the Nobel Peace Prize winner in 2006, is considered to be the funder of joint liability microfinance model, and 'Solidarity Group' system in the Grameen Bank of Bangladesh is regarded as the most successful practitioner in joint liability loan model.

Table 1.

Classification of Commercial Loans.

\begin{tabular}{|c|c|c|}
\hline \multirow{5}{*}{$\begin{array}{l}\text { Credit Models in } \\
\text { Commercial Loan }\end{array}$} & \multirow{2}{*}{$\begin{array}{l}\text { Divided Liability } \\
\text { Loan }\end{array}$} & Independent Responsibility Loan \\
\hline & & $\begin{array}{l}\text { Independent Responsibility Loan + } \\
\text { Financing Guarantee Loan }\end{array}$ \\
\hline & \multirow{3}{*}{$\begin{array}{l}\text { Joint Liability } \\
\text { Loan }\end{array}$} & Joint Guarantee Loan \\
\hline & & $\begin{array}{c}\text { Joint Guarantee Loan + Financing } \\
\text { Guarantee Loan }\end{array}$ \\
\hline & & $\begin{array}{l}\text { Joint Guarantee Loan + Risk } \\
\text { Compensation Fund }\end{array}$ \\
\hline
\end{tabular}


The Government raises risk compensation funds and establishes credit platform. These actions form a loan model that is made up of joint guarantee loan and risk compensation fund. Its essence is a kind of joint liability loan including governmental credit. Once risk compensation funds set up, it can be regarded as the third-party guarantor. The enterprises who apply for loans have to deposit a proportion of reserve money into risk compensation funds based on the amount of loans they get. With expanding in size of loans, the size of risk compensation funds increases and the leverage effect will be amplified (CCB). Specifically, when a company applies for a loan and it is lack of effective amount of guaranteed product, it can turn to risk compensation funds. Then, the company will probably get a higher credit line comparing to divided liability loan. If the company cannot repay the loan or its liquidation of assets cannot compensate the amount of loan, the rest part of the loan will be repaid by risk compensation funds.

\section{Project Management Process of Microfinance}

The Project Management Body of Knowledge (PMBOK) is a project management work of specialized content and workflow definitions of the actual composition of the project management standards. It defines that no matter products projects, services projects or results projects, they can be divided into five stages based on their life cycles, which are initiating, planning, implementation, controlling and ending. The management of project life cycle involves schedule, resource requirements, cost estimates, risk management, procurement plan and so on (Bi \& Deng, 2002).

The difference between PMBOK and C-PMBOK is classification of project risk management knowledge. In specific, PMBOK classifies project risk management as a field while $\mathrm{C}$ PMBOK emphases it as a tool of other fields. This may be one of the reasons that China's projects' risks and probabilities of failure are higher than those in the United States.

General microfinance project management has several essential characteristics. At the initial stage, the lending body sets up the timetable of beginning and ending for applicants' projects of loans. The stages of planning, implementation and controlling focus on risk evaluation of projects of loans and use 'determine whether or not to offer loans, the amount and period of loans' as the achievement of these stages. The ending stage will be realized by completion of offering loans and calling in loans at term.

\section{Work Breakdown Structure (WBS) in Microfinance}

WBS is the synthesis tool in project management. Besides, it is also the important work at the initial stage of a project and in the center of planning stage. According to WBS, a project forms several groups which consist of separated elements that can be submitted. It summaries and defines the scope of the project in a hierarchical mode that the work in each level has detailed and operable definitions.

Work packages are the lowest level of project elements. Generally speaking, work packages are the smallest results that can be submitted and these results can be easily identified for its activities, costs, organization and resource information. A WBS used in project management must be broken down into work packages and then it can be an effective management tool.

Work packages must be structured coding. It is easy to iden- tify the hierarchies, classifications and characteristics of WBS via coding system. To realize WBS structured coding depends on WBS Dictionary, which fully describes and defines works in WBS elements.

According to the basic principles of WBS, a given work can be divided into several task units, called Task for short. A task refers to a set of activities whose form and content is relatively complete and indivisible and one can be done by operators. A project can be a task or it can be divided into several tasks. The tasks are the elements of the project.

Division of work refers to each operator in a project merely do one task, not all tasks, and tasks arranged for each operator are not the same. Division of key points refers to each operator burdens the whole responsibility but focuses on different key points. Each operator's key points of responsibility point to some of the tasks in a project and their key points of responsibility are not the same.

For these reasons, the design of microfinance work package follows not only the basic rules summarized in Effective Work Breakdown Structure by Gregory T. Haugan, it also needs to present the essential characteristics of microfinance institutions, micro and quick. Moreover, microfinance work package emphasizes more on that each person is responsible for one WBS item and the period of each work package is not over forty hours and not in more than four levels (Haugan, 2005).

\section{Basic Assumptions and Approach to Quality Assessment of Microfinance Risk Management}

The quality of any work consists of several interrelated and mutually affected links or procedures, every of which may impact the final quality more or less.

\section{Principles of Ergonomics}

1) Relationship between the Quantity of Work and Error Probability: Based on the principles of reliability, it indicates that any operator has an error probability in work $P_{K}$, work ability $L_{K}$ and maximum work ability $L_{m}$. Different operators have different $P_{K}$ and $L_{K}$. In this paper, it assumed there is relationship between the quantity of work and work error as followings. When $L>L_{K}$, the error probability goes up. If $L$ $>L_{m}$, the operator can barely avoid work errors. The quantity of work for risk management of microfinance can be measured by working time.

This assumption is obvious. When the quantity of work is within the work ability, so long as the operator works carefully, the error probability will be very low. However, no matter how light the quantity of work is, the operator cannot make it without errors. On the contrary, when the quantity of work is more than an operator's work ability, ascending trend of errors will occur with the increase of quantity of work. If the work an operator do is beyond he can do, which means the quantity of work is over the maximum work ability, there must be errors.

2) Inferences on the Relationship between Division of Work or Key Points and Error Probability: According to the assumption, when a project has excessive work, saying quantity of work is over, if division of work comes up, each operator's work decreases, which is helpful to reduce error probability. Similarly, division of key points makes operators focus on their own tasks so that they are able to lower error probabilities of these tasks.

3) Reliability of Work Result: After the analysis above, reli- 
ability closed relates to work ability that is measured by probability and mathematical statistics methods. There are several characteristics of reliability of work result.

Degree of Reliability: the probability that an operator finishes a project within the time and given conditions. It is a function of working time $R(t)$, which is called degree of reliability function.

Probability Density and Distribution Function: if random variable indicates the time from beginning to work error happening, its probability density is $f(t)$; if $t$ indicates a certain time, the degree of reliability is the probability that an operator has not made any mistake within $t$ and it is also the probability when there is $T>t$. (You, Zhang, \& Du, 2003)

$$
R(t)=P(T>t)=\int_{t}^{\infty} f(t) d t
$$

is the distribution function of :

$$
F(t)=P(T \leq t)=\int_{0}^{1} f(t) d t
$$

Because work with errors and work without errors are complementary events, it can be presented as:

$$
R(t)+F(t)=1
$$

so,

$$
\lambda(t)=F^{\prime}(t) / R(t)=f(t) / R(t)
$$

The value of $\lambda(t)$ is similar to $P_{K}$.

\section{Analysis of the Principle of Work Organization}

1) Probability Analysis of Errors Happening in Simultaneity between Two workers: For two given workers, $W_{A}$ and $W_{B}$, the event $W_{A}$ makes mistake is $A$ while the event $W_{A}$ does not make mistake is $A$. Similarly, the event $W_{B}$ makes mistake is $B$ and the event $W_{B}$ does not make mistake is $B$. Suppose there is a project $W$, the error probabilities of $W_{A}, W_{B}$ are $P(A)$ and $P(B)$, respectively. The probability that errors happen in simultaneity between $W_{A}$ and $W_{B}$ is $P(A B)$.

It can be seen from

$$
P(A B)=P(A / B) P(B)=P(B / A) P(A)
$$

that the simultaneous error probability of two operators is not larger than that they make mistakes separately. However, this formula does not show the relationship between $A$ and $B$. Independence in work cannot guarantee independence in error probability.

The relationship between $A$ and $B$ can be showed as:

For two given random variables $X=\{0,1\}$ and $Y=\{0,1\}$, $X=1$ when the event $A$ happens and $X=0$ when the event $A$ happens. The same as $Y=1$ and $Y=0$ refer to the events $B$ and $B$, respectively. So,

$$
P(X=1)=P(A)
$$

and the expect value of $X$ is $E(X)=P(A)$ (Sheng, Xie \& Pan, 2008).

Similarly, $E(Y)=P(B)$. Plus $P(A B)=P(X=1, Y=1)$, then $E(X Y)=P(A B)$.

Suppose $\lambda$ is the coefficient of $X$ and $Y, D(X)$ is the variance of $X$ and $D(Y)$ is the variance of $Y$. In addition,

$$
D(X)=P(A) P(\bar{A}) \text { and } D(Y)=P(B) P(\bar{B}) .
$$

Combine the formulas:

$$
\begin{gathered}
E(X Y)=E(X) E(Y)+\operatorname{COV}(X Y) \\
C O V(X, Y)=\lambda \sqrt{D(X) D(Y)}
\end{gathered}
$$

it gets a result:

$$
P(A B)=P(A) P(B)+\lambda \sqrt{P(A) P(\bar{A}) P(B) P(\bar{B})}
$$

The error probability of two operators is related to individual error probability and their coefficient of error, which is about their knowledge. The more similar their knowledge is, the larger their coefficient will be. Therefore, it is important in practice to make the members of a work team have less similarity in their knowledge, but more complementary.

2) Analysis of Division of Work and Key Points: A given project has $n+m$ tasks and it is done by $W_{A}$ and $W_{B}$ independently. The simultaneous error probability of these two workers is $P(A B)$ and the total number of error tasks is $(n+m) P(A B)$. Suppose the project is done via dividing work, $W_{A}$ is mainly responsible for $n$ tasks and $W_{B}$ is mainly responsible for the rest $m$ tasks. Individual error probability changes in this way. For $n$ tasks, the error probability of $W_{A}$ turns to $P\left(A_{n}\right)<P(A)$ Similarly, $P\left(B_{m}\right)<P(B)$. In $n$ tasks;

$$
\begin{aligned}
P\left(A_{n} B_{n}\right)= & P\left(A_{n}\right) P\left(B_{n}\right) \\
& +\lambda_{n} \sqrt{P\left(A_{n}\right) P\left(\overline{A_{n}}\right) P\left(B_{n}\right) P\left(\overline{B_{n}}\right)}
\end{aligned}
$$

and in $m$ tasks,

$$
\begin{aligned}
P\left(A_{m} B_{m}\right)= & P\left(A_{m}\right) P\left(B_{m}\right) \\
& +\lambda_{m} \sqrt{P\left(A_{m}\right) P\left(\overline{A_{m}}\right) P\left(B_{m}\right) P\left(\overline{A_{m}}\right)}
\end{aligned}
$$

The total number of errors is :

$$
n P\left(A_{n} B_{n}\right)+m P\left(A_{m} B_{m}\right)
$$

So, when $P\left(A_{n} B_{n}\right) \leq P(A B)$ and $P\left(A_{m} B_{m}\right) \leq P(A B)$

$$
n P\left(A_{n} B_{n}\right)+m P\left(A_{m} B_{m}\right) \leq(n+m) P(A B)
$$

Similarly, $P\left(A_{n} B_{n}\right) \geq P(A B)$ and $P\left(A_{m} B_{m}\right) \geq P(A B)$

$$
n P\left(A_{n} B_{n}\right)+m P\left(A_{m} B_{m}\right) \geq(n+m) P(A B)
$$

Based on the assumption, if a project has overload work, the error probability is higher. As known from the inference, the error probability will probably be lower with division of work. This means individual error probability is lower than the simultaneous error probability of two workers without division of work. However, this conclusion has a precondition which is overload work. If the precondition is not satisfied, neither significant enhancement in quality of work for individual nor low simultaneous error probability can be realized with division of work. Consequently, it is crucial to organize work in a reasonable manner (Liu, Zhao, \& Wang, 2003; Ruan, Huang, \& Cai, 2000).

\section{Conclusion}

The management process consists of four functions, which are planning, organizing, leading and controlling, and each function is mutually linked and mutually influenced. WBS belongs to the function of organizing and it reflects its characteristic. WBS provides structural guarantee for management. In such structure, all activities for achieving the goals are divided 
into several groups and formed work units can be done by authorized operators, establishing the rules for upper and lower level, between the horizontal levels. It is also the precondition to realize the functions of leading and controlling in management.

Based on above analysis of essential characteristics of WBS and theory of ergonomics in quality of work, the microfinance risk management with WBS can be designed as Table 2 .

In this paper, although microfinance with WBS contains all

Table 2.

Microfinance with WBS.

\begin{tabular}{|c|c|c|c|}
\hline Class A & Class B & Class C & Class D \\
\hline \multirow{13}{*}{$\begin{array}{l}\text { A sum of } \\
\text { loans }\end{array}$} & \multirow{2}{*}{$\begin{array}{l}\text { Initial collecting } \\
\text { applicants' } \\
\text { information }\end{array}$} & Manual work & \\
\hline & & Systems & \\
\hline & \multirow{6}{*}{$\begin{array}{l}\text { Acceptance of } \\
\text { applications }\end{array}$} & \multirow{3}{*}{ Divided liability loan } & $\begin{array}{c}\text { Independent } \\
\text { responsibility loan }\end{array}$ \\
\hline & & & $\begin{array}{c}\text { Financing guarantee } \\
\text { loan }\end{array}$ \\
\hline & & & $\begin{array}{c}\text { Financing guarantee } \\
\text { loan }\end{array}$ \\
\hline & & Joint liability loan & Joint guarantee loan \\
\hline & & & $\mathrm{RCF}$ \\
\hline & & Investigation & $\begin{array}{c}\text { Review the items } \\
\text { again }\end{array}$ \\
\hline & \multirow{3}{*}{$\begin{array}{l}\text { Examination of } \\
\text { loans }\end{array}$} & $\begin{array}{l}\text { Compliance } \\
\text { examination }\end{array}$ & \\
\hline & & Risk examination & \\
\hline & & Roadshow & \\
\hline & \multirow{2}{*}{ Execution of loans } & Contracting & \\
\hline & & $\begin{array}{c}\text { Management of after } \\
\text { lending }\end{array}$ & Regular audit \\
\hline
\end{tabular}

events from before lending to after lending and its nature of commercial loans and essential characteristics, it still need to be tested and improved in practical microfinance in inclusive financial system.

\section{REFERENCES}

Bi, X., \& Deng, T. (2002). Essentials of project management. Beijing: Chemical Industry Press.

CCB (2008) Shenzhen: Put 15 billion to solve SME financing problems within 5 years.

http://politics.people.com.cn/GB/14562/7631329.html

Chen, M. Y. (2009). Number of SMES in China exceeded ten million. http://news.xinhuanet.com/fortune/2010-05/14/c_12102294.html

Jiao, J. P. (2010). The importance of building inclusive financial sectors. China Finance, 688, 12-13.

Haugan, G. T. (2005). Effective work breakdown structures. Beijing: China Machine Press.

Liu, B. D., Zhao, R. Q., \& Wang, G. (2003). Uncertain programming with applications, chapter 4: Random variables (pp. 32-34). Beijing: Tsinghua University Press.

Liu, J. X., \& Zhao, Y. H. (2011). The analysis of credit structure optimization model based on joint liability. In Review on oversea researches: Proceedings of the 3nd international conference on financial risk and corporate finance management (pp. 592-597). Dalian: Dalian University of Technology Press.

Ruan, J., Huang, Z. X., \& Cai, Z. J. (2000). Applied mathematics, chapter 5: Basic probability theory (pp. 297-353). Beijing: Science Press.

Sheng, J., Xie, S. Q., \& Pan, C. Y. (2008). Probability and mathematiccal statistics, chapter 1: Basic concepts of probability theory (pp. 123). Beijing: Higher Education Press.

United Nations (2005). Shaping, the "Blue Book" on building inclusive financial sectors for development. An issues paper for the global meeting ILO headquarters, Geneva.

You, J. X., Zhang, J. T., \& Du, X. M. (2003). Quality management Technology of reliability (pp. 208-214). Beijing: Science Press.

Zhao, Y. H. (2004). Methods study on risk control of credit management, chapter 6: Risk control of credit contract. Doctoral Dissertation, Shanghai: Tongji University. 